\title{
Characteristics of Mixed Porus Asphalt with Combination of LDPE, CPO and PEN 60/70
}

\author{
Meidia Refiyanni*, Chaira \\ Faculty of Engineering, Universitas Teuku Umar, Aceh Indonesia \\ *Corresponding author E-mail: meidiarefiyanni@utu.ac.id
}

Manuscript received 15 August 2021; revised 1 Sept 2021; accepted 15 Sept 2021. Date of publication 4 Nov 2021

\begin{abstract}
The quality of the road depends on the pavement, drainage conditions, and materials. For this reason, it is necessary to make innovations in improving the quality of road pavement, one of which is increasing the material. There are many types of pavements, one of which is porous asphalt pavement. Porous asphalt has many cavities that is easy for water to pass but has a low stability value with high permeability. This research will utilize Low Density Poly Ethylene (LDPE), as an additive, CPO, and Pen 60/70 in a porous asphalt mixture. The purpose of this study was to determine the characteristics of the porous asphalt mixture by substituting LDPE and CPO for Pen 60/70. The method used in analyzing the characteristics of the porous asphalt mixture refers to the specifications of the Australis Asphalt Pavement Association (AAPA) (2014), with parameters Camtabro Loss (CL), Asphalt Flow Down (AFD), VIM, stability and flow. The gradation used in this study is an open gradation. This research was started from determining the value of Optimum Asphalt Content (KAO), with two variations, namely Variation 1 (1\% LDPE, 10\% CPO, 89\% pen 60/70), variation 2 (5\% LDPE, 10\% CPO, 85\% Pens $60 / 70)$. The KAO value of variation 1 is $5.03 \%$ and the second variation is $4.75 \%$. After obtaining the KAO value, LDPE and CPO are substituted. The test results for the porous asphalt mixture for CL values were $34.12 \%$ and $27.07 \%$, respectively; AFD value of $0.13 \%$ and $0.12 \%$; for the VIM value of $14.90 \%$ and $19.03 \%$; stability value $603.24 \mathrm{~kg}$ and $603.19 \mathrm{~kg}$; and flow values are $5.03 \mathrm{~mm}$ and 4.80 $\mathrm{mm}$. In general, the value obtained from the test meets the required requirements. However, the durability value of the mixture did not meet the requirements, namely $60.15 \%$ and $48.22 \%$, with the condition $>90 \%$.
\end{abstract}

Keywords: LDPE, CPO, Pen 60/70, porous asphalt, AAPA.

\section{Introduction}

Nearly $89-90 \%$ of the mobility of people and goods is carried out on roads, so infrastructure development, especially roads, must be a priority. The infrastructure that most influences the economy, society, culture, defense and security is the highway [1]. The quality of a good highway depends on the pavement, drainage conditions and the material used. One of the materials that determine the quality of the pavement is asphalt. This is because asphalt serves as a binder on the road pavement. As road construction increases, the demand for asphalt also increases. However, it is inversely proportional to the supply of asphalt itself, this is because asphalt is a non-renewable material. To anticipate the supply of asphalt, innovations or research on asphalt is needed [2].

The combination of 25\% CPO and 75\% Asphalt Pen 60/70 has been carried out for the AC-WC mixture. The results of the resulting marshall characteristics meet the characteristic values required by Bina Marga, 2010 but the durability value for the pavement does not meet the requirements [3]. Modifying asphalt with Low Linear Density Poly Ethylene (LLDPE) plastic in terms of Marshall characteristics and Penetration Test on Asphalt Concrete Layer (AC-BC). The test results show the increasing levels of LLDPE, the higher the stability value [4]. Another research that has been carried out is the use of 50\% bot-tom ash and 50\% cement as a filler with retona blend 55 as a binder in a porous asphalt mixture [5] [1].

To produce a mixture that meets the requirements, high quality asphalt with a high softening point is needed [6]. Every year plastic is estimated at 500 billion -1 trillion. If this condition is allowed to continue, it can wrap around the earth's surface. The existence of LDPE is a problem, LDPE is one of the plastic packaging wastes that is often used by the public [6]. Plastic is used as packaging because it has advantages in terms of shape and flexibility, making it easy to carry. In addition to having the advantages of plastic, it also has a negative impact in the form of plastic waste. The use of plastic waste or Low Density Poly Ethylene (LDPE), is one of the innovations made to improve the quality of asphalt. In addition to durability, water is also a consideration in a pavement. Porous asphalt is a pavement that has pores, so it is easy to drain water that passes through the surface of the road pavement. Based on the description above, this research uses Low Density Poly Ethylene (LDPE), as an additive, CPO [7], and Pen 60/70 in a porous asphalt mixture. The purpose of this study 
was to determine the effect of LDPE and CPO substitution on Pen 60/70 in a porous asphalt mixture according to the specifications of the Australian Asphalt Pavement Association (2014) [8] [9].

\section{Literature Review}

Plastics have thermal properties and these properties are not shared by other materials [9]. Thermal properties are the properties by which plastics can be formed into other shapes by heating. Temperature is a factor that affects the formation of plastic. The typical properties of plastics have a melting point ( Tm ), and the value will be different for each type of plastic. In addition, plastic also has a transition temperature value (Tg). LDPE is a type of plastic that has a viscosity value of $0.78 \mathrm{~g} / \mathrm{ml}$, a density of $0.742 \mathrm{~g} / \mathrm{ml}$, a melting point of 1150 $\mathrm{C}$ and easily soluble in tetrachlorocarbon (CCl4). Kadir (2012) in explained that each unit weight of plastic consists of $70 \%$ oil, $16 \%$ gas, $6 \%$ carbon solod and $8 \%$ water [10].

The results of the oil palm plant are oil palm fruit and bunches which are often referred to as FFB (Fresh Fruit Bunches) [11] [12]. The oil palm fruit is divided into several parts [12], namely 56\% fruit fibers and $44 \%$ core. Oil palm fruit that is ready to be harvested will be red with a slight yellowish and shiny appearance. The process of pressing palm fruit will produce pure palm oil which is often referred to as CPO. Crude Palm Oil (CPO) is derived from vegetable oil made from fruit fibers [7].

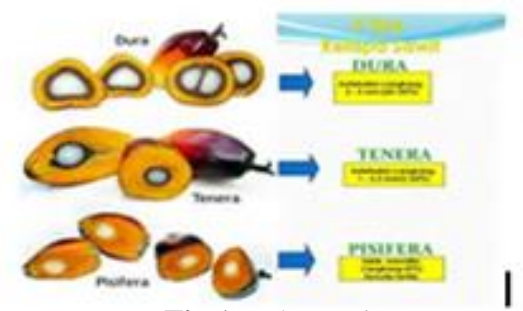

Fig 1. Palm Fruit Parts

\section{Methods}

The initial stage in this research is to collect research materials in the form of: coarse and fine aggregate, asphalt Pen 60/70, CPO and LDPE and cement used as a filler. The aggregate used in this study came from the Keude Linteng stone cruiser, Nagan Regency. The Australian Asphalt Pavement Association (2004) explains that the asphalt content for aggregates with a maximum size of $14 \mathrm{~mm}$ can use an asphalt content of $4.5 \%-6 \%$ of the total mixture to determine the value of the Optimum Asphalt Content (KAO) [2]. There are 4 asphalt content selected for the manufacture of the test object, namely: $4.5 \% ; 5 \% ; 5.5 \%$ and $6 \%$ of the total weight of the mixture as much as 1100 gr. The gradation used for the porous asphalt mixture is an open gradation. This gradation has more coarse aggregate content than fine aggregate so that this gradation has higher air voids than other gradations [13]. For more details, it can be seen in Table 1 , the gradation curve of the porous asphalt mixture with a maximum aggregate size of $14 \mathrm{~mm}$ :

Table 1. Mixed Porous Asphalt With Aggregate Gradation

\begin{tabular}{cc}
\hline Sieve Size $(\mathrm{mm})$ & Weight Passes $(\%)$ \\
\hline 19,00 & 100 \\
\hline 13,20 & $85-100$ \\
\hline 9,53 & $45-70$ \\
\hline 6,70 & $25-45$ \\
\hline 4,76 & $10-25$ \\
\hline 2,38 & $7-15$ \\
\hline 1,19 & $6-12$ \\
\hline 0,595 & $5-10$ \\
\hline 0,297 & $4-8$ \\
\hline 0,149 & $3-7$ \\
\hline 0,074 & $2-5$ \\
\hline Total & 100 \\
\hline Asphalt Content & $4,5-6,0$ \\
\hline
\end{tabular}


The method used in this study is the Australian Asphalt Pavement Association specification (2014). Determination of optimum asphalt content by adjusting the results of asphalt content characteristics, namely VIM, cantabro loss and asphalt flow down. The specification value for determining the Optimum Asphalt Content (KAO), the AAPA method is presented in the following table:

Table. 1 KAO Determination Specification

\begin{tabular}{ccc}
\hline No. & Specification & Condition \\
\hline 1 & Cantabro Loss 9\%) & Max. 35\% \\
\hline 2 & Asphalt Flow down (AFD) (\%) & max. 0,3\% \\
\hline 3 & Void in Mix (VIM) (\%) & $18-25$ \\
\hline 4. & stability (Kg) & Min. 550 \\
\hline 5. & Flow (mm) & $2-6$ \\
\hline 6. & Residual stability (Durability) & Min. 90\% \\
Source : Australia Asphalt Pavement Association (AAPA) (2014)
\end{tabular}

\section{Cantabro Loss (CL)}

Cantabro Loss is a test to see the ability of a pavement in resistance to grain release. The test object will be rotated with a "Los Angeles" machine and rotated for 300 revolutions without an iron ball. Resistance of the test object to grain release. According to the AAPA specification, 2014 the $C L$ value $<35 \%$, the CL value can be calculated by the equation:

$$
\mathrm{A}_{1}=\left[\left(\mathrm{m}_{1}-\mathrm{m}_{2}\right) / \mathrm{m}_{1}\right] \times 100 \%
$$

\section{Asphalt Flow Down (AFD)}

Asphalt Flow Down (AFD) is the maximum asphalt content value that can be homogeneously mixed with aggregate without asphalt separation, AFD value $<0.3 \%$. AFD value can be calculated using the formula:

$$
\mathrm{AFD}=\left(\mathrm{m}_{3}-\mathrm{m}_{1} / \mathrm{m}_{2}-\mathrm{m}_{1}\right) \times 100 \%
$$

Void in Mix (VIM)

Void In Mix (VIM) is the percentage of voids in the mixture, the VIM value according to AAPA, (2004) is $18-25 \%$. VIM value can be calculated by the formula:

$$
\mathrm{n}=100-100 \mathrm{x}(\mathrm{g} / \mathrm{h})
$$

\section{Stability Test}

Stability is the ability of the pavement to accept traffic loads without changes in shape such as waves, grooves or bleeding. The indicated value is $>550 \mathrm{~kg}$ with the formula:

$$
\mathrm{S}=\mathrm{p} \times \mathrm{q} \times \mathrm{r}
$$

\section{Flow Test}

Flow is the state of change in the shape of the pavement at the time it will collapse which is obtained by reading the dial flow on the Marshall tool.

Each percentage of asphalt content will be combined with LDPE, CPO and pen 60/70. The combination consists of two variations, namely Variation 1 (1\% LDPE: 10\% CPO: 89\% Pen 60/70), and Variation 2 (5\% LDPE: 10\% CPO: 85\% Pen 60/70) of the total weight of asphalt required in the mix for moderate traffic with 50 collisions. The number of specimens for each asphalt content consists of 6

\begin{tabular}{|c|c|c|c|c|c|c|c|c|c|c|c|c|c|}
\hline \multirow{3}{*}{ Variation } & \multicolumn{4}{|c|}{ Marshall Test } & \multicolumn{4}{|c|}{ Cantabro Loss (CL) } & \multicolumn{4}{|c|}{ Asphalt Flow Down (AFD) } & \multirow{3}{*}{$\begin{array}{l}\text { Number } \\
\text { of Test } \\
\text { Items }\end{array}$} \\
\hline & \multicolumn{12}{|c|}{ Asphalt Content Percentage } & \\
\hline & $4.5 \%$ & $5 \%$ & $5.5 \%$ & $6 \%$ & $4.5 \%$ & $5 \%$ & $5.5 \%$ & $6 \%$ & $4.5 \%$ & $5 \%$ & $5.5 \%$ & $6 \%$ & \\
\hline V1 & 6 & 6 & 6 & 6 & 6 & 6 & 6 & 6 & 6 & 6 & 6 & 6 & 7 \\
\hline V2 & 6 & 6 & 6 & 6 & 6 & 6 & 6 & 6 & 6 & 6 & 6 & 6 & 72 \\
\hline \multicolumn{13}{|c|}{ Total } & 144 \\
\hline
\end{tabular}
specimens with two variations so that the number of specimens needed in this study to determine the Optimum Asphalt Content (KAO) for the two variations is 144 specimens with the following details:

Table 2. Details of the number of test objects for determination of KAO 


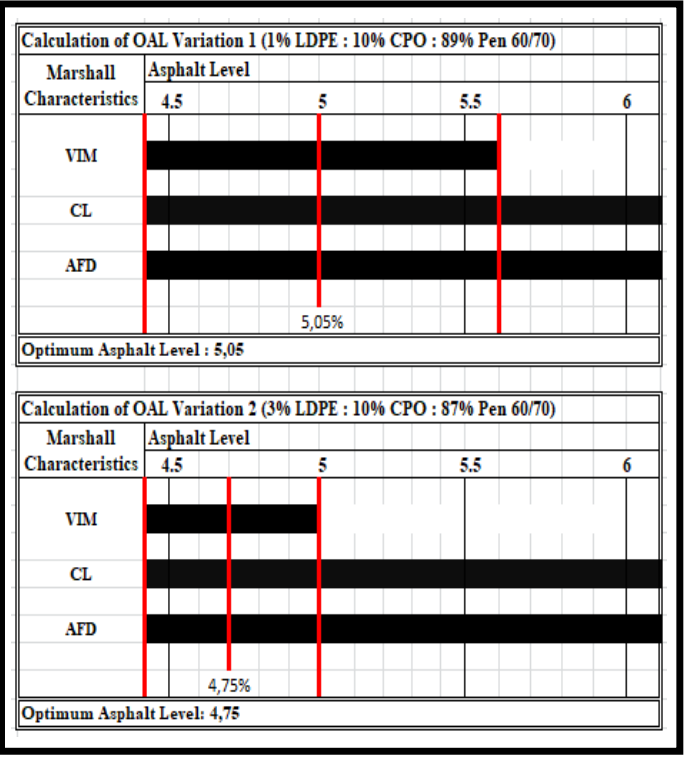

Fig 2. Determining the Optimum Asphalt Content (KAO)

After obtaining two KAO values for each variation. The next step is to make a test object by substituting LDPE, CPO and Pen 60/70 into each variation. The number of specimens for each optimum asphalt content is 6 specimens with two variations. Determination of the characteristics of the porous asphalt mixture consists of: Marshall test, Cantabro Loss (CL) test, and Asphalt Flow Down (AFD) test so that the required number of test specimens is 72 specimens with the following details:

Table 3. Details of Number of Test Objects for Determination of the Characteristics of Porous Asphalt Mixture.

\begin{tabular}{|c|c|c|c|c|c|c|c|}
\hline \multirow{3}{*}{$\begin{array}{l}\text { Varia- } \\
\text { tion }\end{array}$} & Marsha & Test & Canta & _oss (CL) & Asphalt Fl & $\mathrm{vn}$ (AFD) & \multirow{3}{*}{$\begin{array}{l}\text { Number of } \\
\text { Test Items }\end{array}$} \\
\hline & \multicolumn{6}{|c|}{ Optimum Asphalt Content (KAO) } & \\
\hline & $5.05 \%$ & $4.75 \%$ & $5.05 \%$ & $4.75 \%$ & $5.05 \%$ & $4.75 \%$ & \\
\hline V1 & 6 & 6 & 6 & 6 & 6 & 6 & 36 \\
\hline $\mathrm{V} 2$ & 6 & 6 & 6 & 6 & 6 & 6 & 36 \\
\hline \multicolumn{7}{|c|}{ Total } & 72 \\
\hline
\end{tabular}

\section{Results and Discussion}

The test to determine the optimum asphalt content of the porous asphalt mixture in variation 1 (1\% LDPE, 10\% CPO, 89\% Pen $60 / 70)$, and variation 2 (5\% LDPE, 10\% CPO, 85\% Pen 60/70) obtained optimum asphalt of $5.03 \%$ and $4.75 \%$. These tests include: Voids In Mix (VIM), Cantabro Loss (CL), and Asphalt Flow Down (AFD).

Table 4. Recapitulation of test results to determine KAO

\begin{tabular}{|c|c|c|c|c|c|c|c|c|c|c|}
\hline \multirow{3}{*}{ No. } & \multirow{3}{*}{ Characteristics } & \multicolumn{8}{|c|}{ Asphalt Content Percentage } & \multirow{3}{*}{ Spesification } \\
\hline & & \multicolumn{2}{|c|}{$4.5 \%$} & \multicolumn{2}{|c|}{$5 \%$} & \multicolumn{2}{|c|}{$5.5 \%$} & \multicolumn{2}{|c|}{$6 \%$} & \\
\hline & & V1 & V2 & V1 & V2 & V1 & V2 & V1 & $\mathrm{V} 2$ & \\
\hline 1. & VIM & 18.30 & 18.20 & 18.85 & 18.35 & 18.67 & 39.39 & 25.24 & 37.76 & $18-25(\%)$ \\
\hline 2. & Cantabro Loss & 28.55 & 27.75 & 28.16 & 28.34 & 28.00 & 28.42 & 27.99 & 28.08 & $<35(\%)$ \\
\hline 3. & $\begin{array}{l}\text { Asphalt Flow } \\
\text { Down (AFD) }\end{array}$ & 0.11 & 0.21 & 0.11 & 0.22 & 0.11 & 0.22 & 0.22 & 0.19 & $<0.3(\%)$ \\
\hline
\end{tabular}

After obtaining the optimum asphalt content value (KAO), then proceed with the manufacture of test specimens with KAO obtained to determine the characteristics of the porous asphalt mixture, namely Marshall Test, Cantabro Loss (CL), and Asphalt Flow Down (AFD) testing.

Table 5. Test Result Marshall Test, CL, dan AFD

\begin{tabular}{ccccccc}
\hline \multirow{2}{*}{$\begin{array}{c}\text { Mixed Variations } \\
(\% \text { KAO) }\end{array}$} & $\begin{array}{c}\text { Stability } \\
(>550 \mathrm{Kg})\end{array}$ & $\begin{array}{c}\text { Residual Sta- } \\
\text { bility }(>90 \%)\end{array}$ & $\begin{array}{c}\text { Flow } \\
(2-6 \mathrm{~mm})\end{array}$ & $\begin{array}{c}\text { VIM } \\
(18-25 \%)\end{array}$ & $\begin{array}{c}\text { Loss } \\
(<35 \%)\end{array}$ & $\begin{array}{c}\text { Asphalt Flow } \\
\text { Down }(<0.3 \%)\end{array}$ \\
\hline V1 (5.05) & 603.24 & 60.15 & 5.03 & 14.90 & 34.12 & 0.13 \\
\hline V2 (4.75) & 603.19 & 48.22 & 4.80 & 19.03 & 27.07 & 0.12 \\
\hline
\end{tabular}

The Cantabro Loss test for variation 2 (5\% LDPE, 10\% CPO, 85\% Pen 60/70) showed a smaller value than the value in variation 1 (1\% LDPE, $10 \%$ CPO, $89 \%$ Pen 60/70), This shows that the combination of asphalt variation 2 occurs when the asphalt binds to the aggregate which is small so that the resistance of the porous asphalt mixture to wear becomes large. The increase in the percentage of LDPE content results in a smaller AFD value, this is due to the stronger asphalt separation level in the mixture. VIM is the percentage of voids in the mixture. The value of VIM increases as the asphalt content in the mixture decreases. The lower the asphalt content in the mixture, the larger the air voids in the mixture. This is due to the small number of cavities filled with asphalt. The flow value decreased as the 
asphalt content in the mixture decreased, but the LDPE percentage increased. This is due to the influence of a large percentage of LDPE so that the elasticity level of the asphalt content is reduced. Inversely proportional to stability where the greater the value of stability along with increasing asphalt content and decreasing the percentage of LDPE in the mixture. This is due to the good mixing of LDPE and asphalt which causes the stability value to increase.

Tests using KAO on both variations can be seen that in general the characteristics of the porous asphalt mixture are in accordance with the requirements indicated by AAPA (2014) but not for residual stability. The use of LDPE as an additive in porous asphalt mixtures helps to improve the characteristics of the mixture. Variations with larger LDPE produce better characteristic values than those with less LDPE. This can be seen in the resistance of the mixture to the release of less grains.

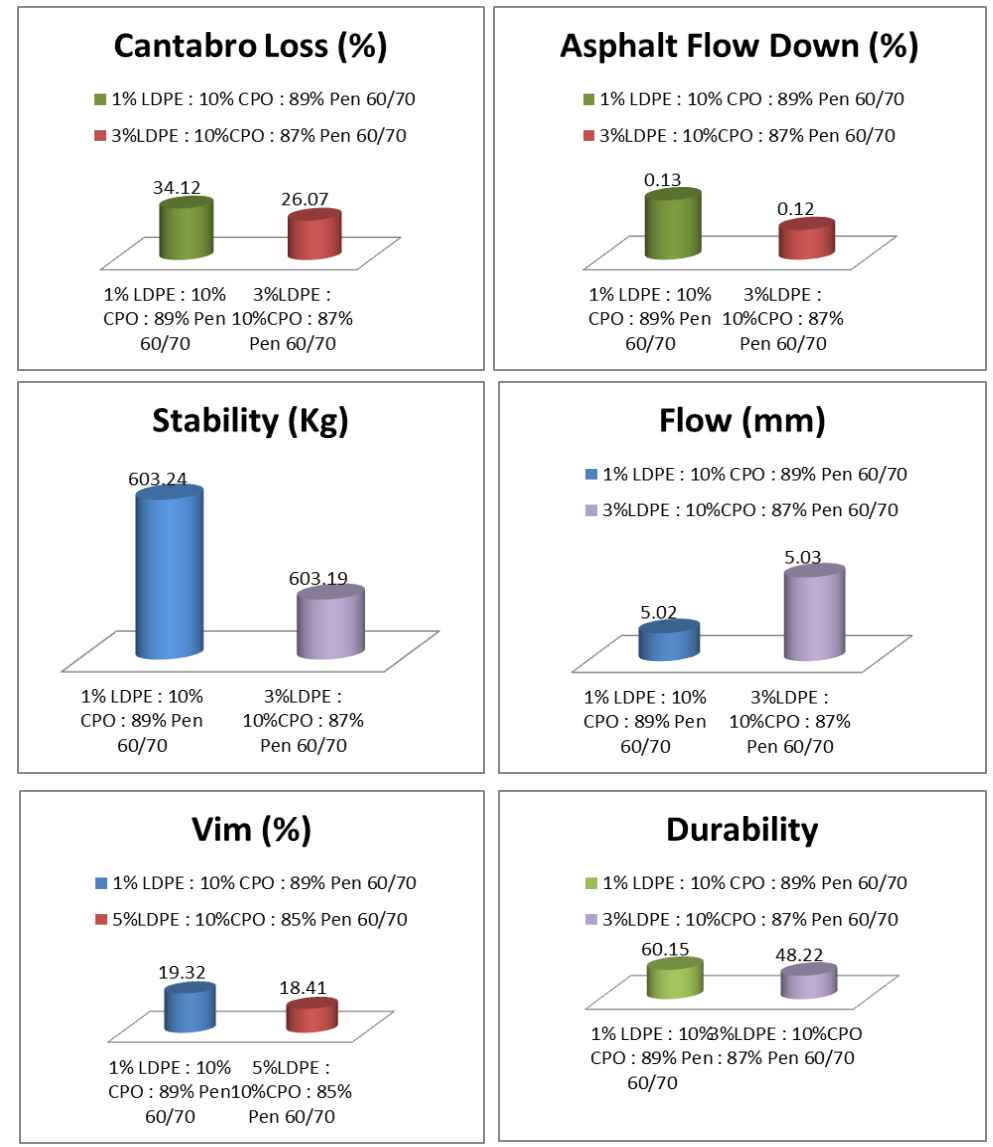

Fig 3. Test Results of Porous Asphalt Mixture Characteristics

\section{Conclusion}

Optimum Asphalt Content Value (KAO) for each variation is $5.05 \%$ and $4.75 \%$. The greater the percentage of asphalt content but a small percentage of LDPE in the mixture, the greater the stability value produced is $603.24 \mathrm{Kg}$ and conversely the smaller the percentage of asphalt with greater LDPE substitution results in a lower stability value of $603.19 \mathrm{Kg}$. In contrast to the Flow value, the greater the percentage of asphalt content with a small LDPE substitution produces a larger value of $5.03 \mathrm{~mm}$. This is due to the high asphalt content in the mixture so that the elasticity level of the porous asphalt mixture increases. The smaller the asphalt content in the mixture, the greater the VIM value, but on the contrary the greater the percentage of asphalt content in the mixture, the smaller the voids in the mixture, namely $14.90 \%$ and $19.03 \%$. The decrease in asphalt content with a large LDPE substitution causes a decrease in the CL value, which means that the resistance of the mixture to grain release is getting smaller, namely $27.07 \%$, but for a high asphalt content with a small LDPE substitution, it will produce a larger CL value. Likewise, the AFD value also decreased by $0.1 \%$ from $0.13 \%$ due to the small asphalt content with large LDPE substitution. This indicates that the level of separation between asphalt and aggregate becomes smaller. In general, the characteristic values for the porous asphalt mixture meet the standards required by AAPA, 2004, but not for the durability values, namely $60.15 \%$ and $48.22(>90 \%)$.

\section{Acknowledgement}

Thank you to all those who have helped in completing this research. Do not forget the researchers say many thanks to the University of Teuku Umar which has provided research funding support until the completion of this article.

\section{References}

[1] S. G., H. A., and M. B., "The Characteristics of Asphalt Concrete Binder Course (AC-BC) Mixture with Bottom Ash as Aggregate Substitute," Civ. Eng. Dimens., vol. 17, no. 1, 2015, doi: 10.9744/ced.17.1.29-37.

[2] S. Romadhona, F. Kurniawan, and J. Tistogondo, "Project Scheduling Analysis Using the Precedence Diagram Method (PDM) Case Study: Surabaya's City Outer East Ring Road Construction Project (Segment 1),” Int. J. Eng. Sci. Inf. Technol., vol. 1, no. 2, 
2021, doi: 10.52088/ijesty.v1i2.56.

[3] M. Refiyanni and azwanda, "Subtitusi CPO Terhadap ASPHALT PEN 60 / 70 Pada Campuran Asphalt Concrete Wearing Course (AC-WC)," vol. 5, no. 1, pp. 360-367, 2020.

[4] P. Pratomo, H. Ali, and S. Diansari, "Aspal Modifikasi dengan Penambahan Plastik Low Liniear Density Poly Ethylene ( LLDPE ) Ditinjau dari Karakteristik Masrhall dan Uji Penetrasi pada Lapisan Aspal Beton ( AC-BC ),” J. Rekayasa, vol. 20, no. 3, pp. 155166, 2016.

[5] Chaira, M. Refiyanni, and Azwanda, "Characteristics of Porous Asphalt Mixture by Using a Bottom Ash Boiler as a Filler," J. Phys. Conf. Ser., vol. 1764, no. 1, 2021, doi: 10.1088/1742-6596/1764/1/012167.

[6] T. W. Suroso, "Aspal Modifikasi dengan Penambahan Plastik Low Linier Density Poly Ethylene (LLDPE) di Tinjau dari Karakteristik Marshall dan Uji Penetrasi pada Lapisan Aspal Beton( AC-BC)," J. Jalan dan Jemb., vol. 26, no. 2, pp. 1-16, 2009, doi: $10.12777 /$ mkts.16.3.208-222.

[7] J. Hidayati, S. Sukardi, A. Suryani, A. M. Fauzi, and S. Sugiharto, "Palm Oil Plantation Revitalization Model for The Agroindustry Development," Int. J. Adv. Sci. Eng. Inf. Technol., 2018, doi: 10.18517/ijaseit.8.2.4148.

[8] Z. Soares Lopes, F. Kurniawan, and J. Tistogondo, "Case Study of Public-Private Partnership on Infrastruc-ture Projects of Tibar Bay Port in Timor-Leste," Int. J. Eng. Sci. Inf. Technol., vol. 1, no. 3, 2021, doi: 10.52088/ijesty.v1i3.79.

[9] R. Dewi, N. Sylvia, and M. Riza, "The Effect of Rice Husk and Saw Dusk Filler on Mechanical Property of Bio Composite from Sago Starch,” Int. J. Eng. Sci. Inf. Technol., vol. 1, no. 3, 2021, doi: 10.52088/ijesty.v1i3.113.

[10] M. S. Arif, R. Durrotun Nasihien, and H. Sutowijoyo, "BIM Implementation in Mall Laves Project Construction Surabaya," Int. J. Eng. Sci. Inf. Technol., vol. 1, no. 2, 2021, doi: 10.52088/ijesty.v1i2.49.

[11] R. Candra Fitrian and A. Sumarno, "Study of the Effect Clay Substitution with Wood Sawdust and Hydroton on Compressive Strength, Density and Water Absorption of Red Brick Case Study of Traditional Red Brick Industry in Singgahan Village,” Int. J. Eng. Sci. Inf. Technol., vol. 1, no. 1, 2021, doi: 10.52088/ijesty.v1i1.103.

[12] N. Sylvia, Y. Yunardi, H. Husni, and A. Muslim, "Simulation of CO2 Gas Adsorption Process Flow at Cyclone Gas Outlet in Palm Oil Mills Using Computation Fluid Dynamic Simulation," Int. J. Eng. Sci. Inf. Technol., vol. 1, no. 3, 2021, doi: 10.52088/ijesty.v1i3.112.

[13] S. Ali Rafsanjani, F. E. Rooslan Santosa, and R. Durrotun Nasihien, "Analysis of Planning for Clean Water Needs at Grand Sagara West Surabaya Hotel With the Green Buillding Concept," Int. J. Eng. Sci. Inf. Technol., vol. 1, no. 2, 2021, doi: 10.52088/ijesty.v1i2.55. 